\title{
IoT-based Drip Irrigation Monitoring and Controlling System using NodeMCU and Raspberry Pi
}

\author{
I Nyoman Kusuma Wardana ${ }^{1}$ \\ Department of Electrical Engineering \\ Politeknik Negeri Bali \\ Badung, Bali, Indonesia \\ ${ }^{1}$ kusumawardana@pnb.ac.id
}

\author{
Padma Nyoman Crisnapati², Komang Agus Ady \\ Aryanto $^{3}$ \\ Department of Computer System \\ STIKOM Bali \\ Denpasar, Bali \\ ${ }^{2}$ crisnapati@stikom-bali.ac.id, ${ }^{3}$ agus_ady@stikom-bali.ac.id
}

\author{
Ngakan Nyoman Kutha Krisnawijaya ${ }^{4}$ \\ Department of Electrical Engineering \\ Universitas Pendidikan Nasional \\ Denpasar, Bali \\ ${ }^{4}$ ngakankutha@undiknas.ac.id
}

\author{
I Wayan Aditya Suranata ${ }^{5}$ \\ Postgraduate Program \\ Universitas Pendidikan Ganesha \\ Singaraja, Bali, Indonesia \\ 5aditya@narin.co.id
}

\begin{abstract}
Drip irrigation can be applied in greenhouse farming system, which small amounts of water and fertilizer can be feed uniformly to the crop root zone. In this work, an IoTbased drip irrigation monitoring and controlling strategy for greenhouse farming systems is proposed. It aims to automatically control the AB-mix nutrition feeding system for the plants. Each sensor and actuator involved in this system was developed to be a single object. Then, the respective objects could be programmed accordingly to perform their own function such as controlling the pumps, controlling the valve, detecting the nutrient level, sensing the soil humidity, etc. Each object has a unique identity to allow a streamlined communication between gateway and the objects by employing a light MQTT protocol. The MQTT protocol needs two components namely MQTT Client and MQTT Broker. The MQTT broker was installed on Raspberry Pi by using Mosquitto platform whereas the MQTT Client was installed on each NodeMCU for sensing or controlling the environmental parameters involved in drip irrigation process. Finally, a realtime data acquisition from sensors and actuators can be monitored through a web-based interface.
\end{abstract}

Keywords-greenhouse; drip irrigation; NodeMCU; Raspberry $P i, M Q T T$

\section{INTRODUCTION}

Greenhouse farming system substantially manage effectively the uses of water, land, and energy for crop production [1]. The controllable environment in greenhouses can provide more suitable place for crops growth [2], and this concept can be so called controlled environment agriculture (CEA) [3,4]. The common activities applied in greenhouse farming system are monitoring environmental parameters like soil fertility and temperature, mineral content, moisture level, diseases detection, irrigation, etc [5]. Among these activities, water management is the major concern, especially in semiarid or arid area. The artificial application of water for growing crops is called as irrigation [6,7]. There are several irrigation techniques available, and one of the is drip irrigation. Drip irrigation also known as micro irrigation is artificial method to effectively utilize water by allowing water to drip slowly to the roots of plants $[7,8]$.

Plenty of research work have been done to control and monitor the drip irrigation technique. A processor-based controller like Arduino [8] and ARM9 [6] were implemented to control the operation of drip devices. Beside the controller, the communication is also essential. Wireless control for actuators by using Zigbee or Wi-fi [7], GSM [9], and ISM communication [10] have been developed.

In this work, the concept of Internet of Things (IoT) by implementing the NodeMCU board, Raspberry Pi and webbased interface is proposed. The MQTT protocol is utilized since it is suitable for many IoT applications.

\section{Methodology}

\section{A. Drip Irrigation Process}

In this research, the proposed drip irrigation system is shown in Figure 1. There are four tanks containing different liquid for irrigation purpose. These tanks were filled by Anutrition only, B-nutrition only, water only, and AB-mix and water. According to [11], the crops need both macro-nutrient $(\mathrm{N}, \mathrm{P}, \mathrm{S}, \mathrm{K}, \mathrm{Ca}$, and $\mathrm{Mg}$ ) and micro-nutrient $(\mathrm{B}, \mathrm{Cl}, \mathrm{Cu}, \mathrm{Fe}$, $\mathrm{Mn}, \mathrm{Mo}$, and Z). A-nutrition and B-nutrition are commercially sold in different packages since the Calcium contained in Anutrition should not be mixed with Sulphate and Phosphate contained in B-nutrition [12]. The first three liquids filled in different tanks (water, A-nutrition, and B-nutrition) will be mixed in the fourth tank resulting AB-mix nutrition. To suck these liquids with proper time intervals, three different pumps were required. Provision of proper nutrition affect the plants growth [12]. The AB-mix concentrate can be evaluated by measuring the electrical conductivity (EC) [11]. The greater 
EC value, the more concentrated the AB-mix. Each crop needs a different EC value. Lettuce (Lactuca sativa) for example, will grow properly with EC values between $0.50-1.55 \mathrm{mS} / \mathrm{cm}$ [11], [13]. However, in this work, instead of concerning on how to produce a proper AB-mix EC value for a certain crop, Authors focus on how to control the instruments involved in drip irrigation system. The time intervals for pump operations were selected for a certain time regardless the EC value needed for a particular crop.

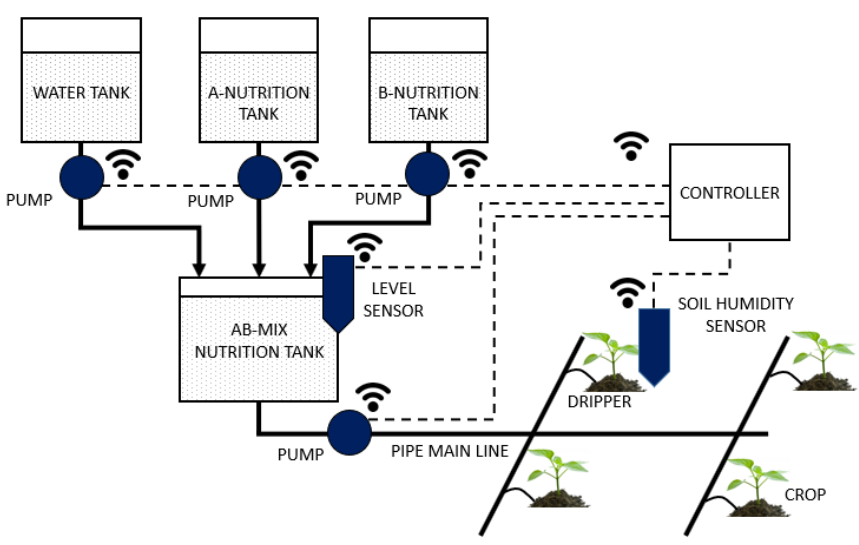

Fig. 1. Drip irrigation system

To control the process, two kind of sensors were applied. The water level sensor was used to detect the level of AB-mix whereas the soil humidity sensor was placed in the crop root to measure the humidity condition. In this works, the water, Anutrition, and B-nutrition tanks were not equipped with level sensors. It was assumed that these liquids are already filled in their respective tanks and ready to be sucked by the pumps. Sensors and actuators (pumps) were wirelessly connected to the controller by using NodeMCU.

\section{B. Monitoring and Controlling System Workflow}

As shown in Figure 2, the system workflow can be divided into several processes, namely controller, data communication, data analysis and data visualization. In the controller process, sensors were used to collect the environmental data, while actuator were employed for controlling the instruments. The acquired data were sent to the Broker by using the MQTT Protocol. Broker is dedicated as a space for the data to do a filtering process before they are sent to the Clients. There are many ways to receive data from the Clients. In this research, the Socket I/O based on Python programming was implemented. The programming part is powered by Paho MQTT Library.

The broker was installed on Raspberry Pi powered by Raspbian operating system which is called Raspbian Jessie. It is selected since Jessie is stable (numerous bugs were fixed) [14]. The applied Broker is so called Mosquitto. Mosquitto provides a lightweight server for MQTT protocol. Therefore, it is suitable for embedded and low-power machine [15]. To support the communication between Broker and Sockets, OpenHAB was applied. The OpenHAB is a powerful and flexible engine to design rules suitable for Raspberry Pi machine [16].
The acquired data will be automatically processed to comply the MySQL database format. Finally, the analysed data will be shown on the web interface. Based on the web interface, users can monitor the level of AB-mix tank and the soil humidity. Moreover, each pump can be controlled manually by clicking the button on the web interface.

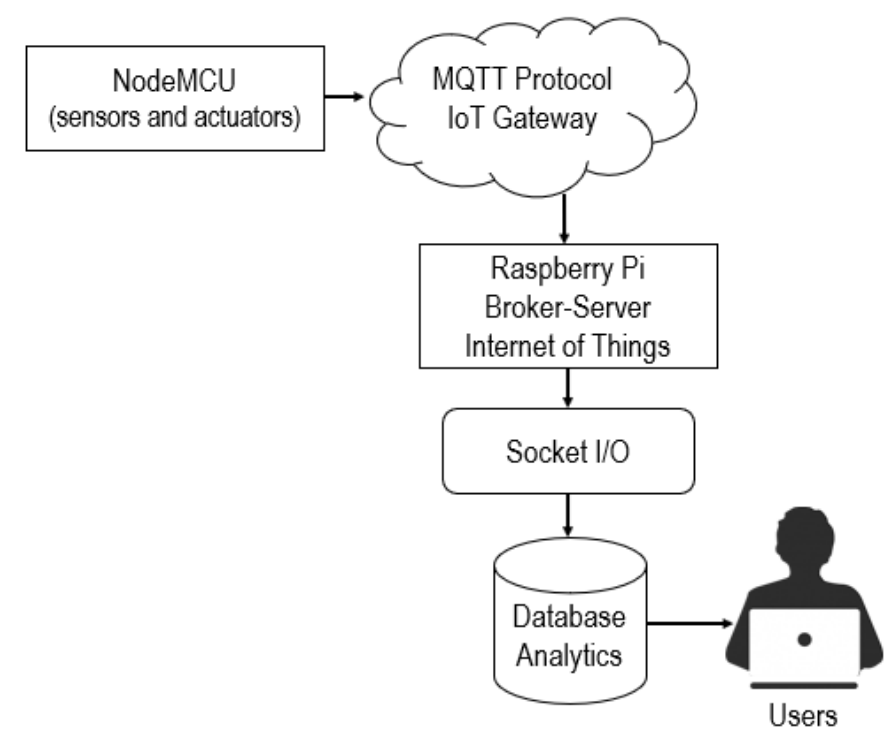

Fig. 2. System workflow

\section{Hardware Object Desain}

In this work, some hardware modules dedicated for drip irrigation purposes were created. These modules are collected to build objects, and each object has its own functions. The controller of each object is powered by a single NodeMCU ESP12E board. This board is equipped by several features, such as Pulse Width Modulation (PWM), Inter-Integrated Circuit (I2C), Analog-to-Digital Converter (ADC), 1-Wire, and GPIO ports which is suitable for the wireless-based automation purposes. The NodeMCU board provides a firmware for wireless platform through a $\mathrm{Wi}-\mathrm{Fi}$ communication protocol. Based on this feature, the NodeMCU can act both as an Access Point or as a station [17].

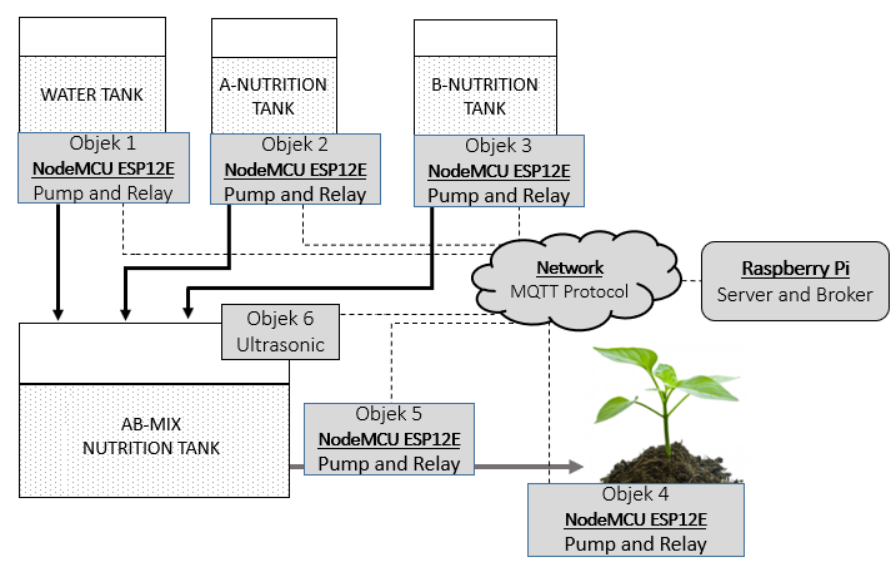

Fig. 3. Hardware objects 
As shown in Figure 3, there are six hardware objects dedicated for drip irrigation process. Object 1, 2, 3 and 5 are intended to control the relay contact in order to drive the pump. These four objects act as actuators, whereas both Object 4 and 6 are functioning as sensors. The Object 5 collect the data for soil humidity, and Object 4 is used for collecting AB-mix level data. In this work, an ultrasonic sensor is applied as the level sensor.

\section{Software Design}

The software design schematic for drip irrigation system is shown in Figure 4. The software part contains a web-based interface. Written in modern web programming language, the interface is compatible with all mobile device displays. Through this web interface, Clients are able to control the functions of whole objects.

The server communication management is controlled by broker MQTT. This protocol is dedicated to control sending process (publish) and receiving process (subscribe). Message Queuing Telemetry Transport (MQTT) is a protocol run on TCP/IP. The MQTT is suitable for many Internet-of-Things (IoT) application compared with HTTP protocol since it more robust to handle a huge of tiny data transferring process [18].

In MQTT, the term so called Topic is also widely used. The topic acts as filter for broker to send each massage for the clients. In other word, topic acts a reference so that there is no communication interference between clients. All communication process between object must pass the broker before reach the clients. By support of Socket, clients can receive data from broker for the further analysis, either to store them in the database or to display them on the web-based interface.

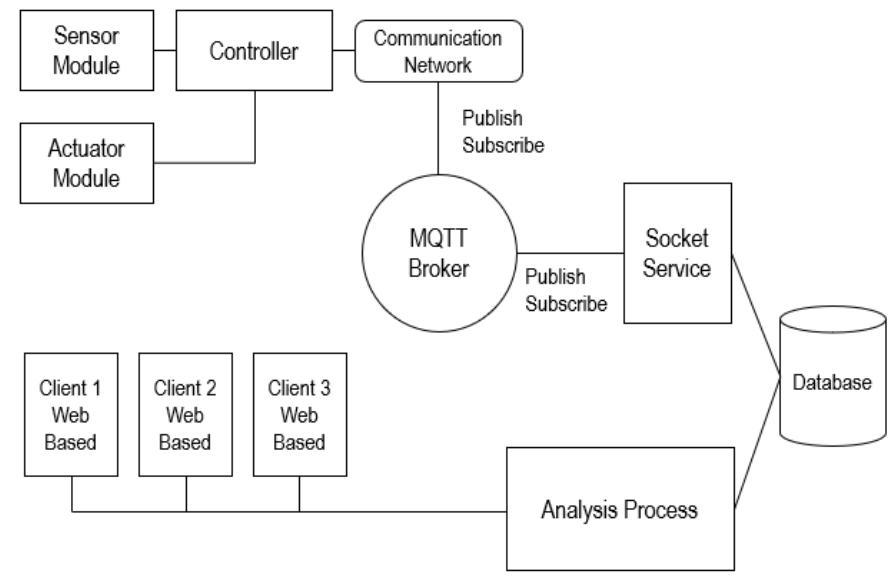

Fig. 4. Software design schematic

\section{RESULT AND DISCUSSION}

The web interface was designed by combining graphs, buttons and values, as shown in Figure 5. The environmental parameter values acquired by objects are sent to the broker/server and then they will be processed based on topic requested by client. To collect the values stored by the broker, a WebSocket written in Python programming language is implemented. The WebSocket acts as a connector between broker and clients. The obtained values will be displayed on the interface by using JavaScript library so called Google Chart. The Google Chart is an interactive web service suitable for displaying graphs and other data.

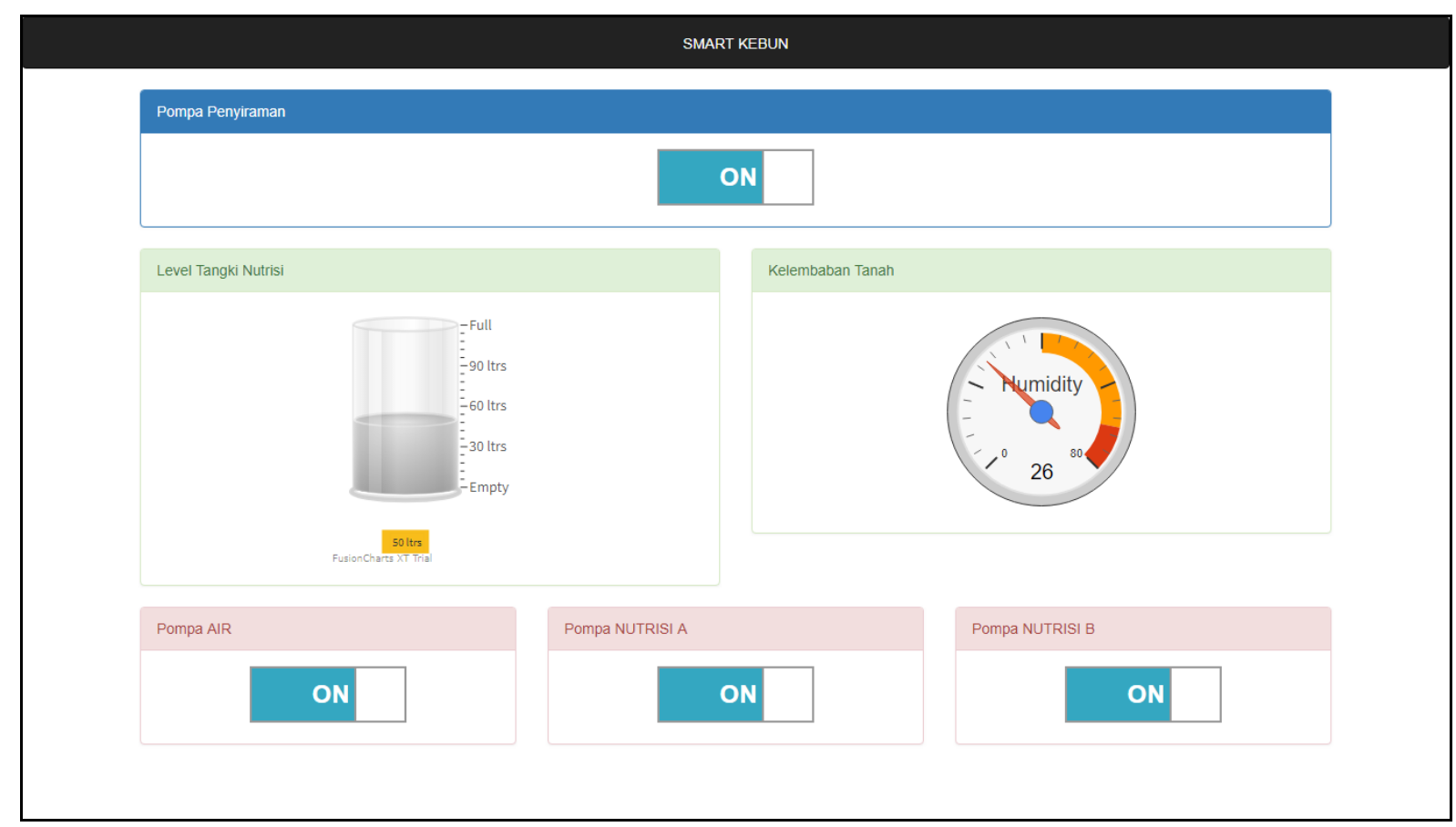

Fig. 5. Web-based interface for drip irrigation system 
Beside monitoring the environmental data, the user can control manually the objects by clicking the ON/OFF button for the respective actuators. The control algorithm was programmed using jQuery library. The command written on a specific function is sent to broker/server through the Socket. The received control command will be processed by the broker based on the topic. If the topic is correctly identified, the command will be sent to the respective module.

\section{CONCLUSION}

In this work, drip irrigation system for greenhouse is proposed. It aims to automatically control the AB-mix nutrition feeding system for the plants. Each sensor and actuator involved in this system was developed to be a single object. The system utilizes the abilities of NodeMCU dan Raspberry $\mathrm{Pi}$ boards. According to the experiments, it is concluded that the control system works accordingly to run the drip irrigation procedure.

\section{ACKNOWLEDGMENT}

The Authors sincerely thank to the Ministry of Research, Technology and Higher Education Republic of Indonesia for research funding through the agreement with Politeknik Negeri Bali. This research is funded by DRPM Dosen Pemula scheme with contract number 013/SP2H/LT/DRPM/2018 and SP DIPA-042.06.1.40156/2018 dated on December 5, 2017.

\section{REFERENCES}

[1] J.Liu, "Design and Implementation of an Intelligent EnvironmentalControl System: Perception, Network, and Application with Fused Data Collected from Multiple Sensors in a Greenhouse at Jiangsu, China," Int. J. of Dist. Sensor Net., vol.12(7), pp. 1-10, July 2016.

[2] J.Yuhan, J.Yiqiong, L.Ting., Z.Man, S.Sha, \& L. Minzan, “An improved method for prediction of tomato photosynthetic rate based on WSN in greenhouse,” Int. J. of Agri. \& Bio. Eng., vol. 9(1), pp. 146, 2016.

[3] R.R. Shamshiri, F. Kalantari, K.C. Ting, K.R. Thorp, I.A. Hameed, C. Weltzien, D. Ahmad, \& Z.M. Shad, "Advances in greenhouse automation and controlled environment agriculture: A transition to plant factories and urban agriculture,” Int. J. of Agri. \& Bio. Eng., vol. 11(1), pp. 1-22, 2018.
[4] M. Suraj, E.I. Ekwue, \& R.A. Birchc, "A Controlled Environment Agriculture Greenhouse for the Caribbean Region," The West Indian J. of Eng., vol. 40(2), pp. 10-16, 2018.

[5] E. Soorya, M. Tejashree, P. Suganya, "Smart drip irrigation system using sensor networks,” Int. J. of Scient. \& Eng., vol. 4(5), pp. 2229 5518, May 2013.

[6] G. Kavianand, V.M. Nivas, R. Kiruthika, \& S. Lalitha, "Smart Drip Irrigation System for sustainable Agriculture," IEEE International Conference on Technological Innovations in ICT For Agriculture and Rural Development, 2016.

[7] H.H. Aniket \& M.K. Sengupta, "Automatic Control of Drip Irrigation System \& Monitoring Of Soil by Wireless," IOSR J. of Agri. \& Vet. Sci., vol. 7(4), April 2014.

[8] P. S. Bangare, R. Patil, Z. Khatib, Z. Khatib, \& K. Mangalgiri, "Automated Drip Irrigation System Using Cloud Computing," Imperial J. of Interdisciplinary Research, vol. 2(6), 2016.

[9] A.R. Tupe, A.A. Gaikwad, \& S.U. Kamble, "Intelligent Drip Irrigation System," Int. J. of Innovative Research in Adv. Eng., vol. 2(2), February 2015.

[10] I N. K. Wardana, P.I. Ciptayani, \& I W.A. Suranata, "Sub-1GHz wireless sensing and control instruments for greenhouse farming system," J. of Phy.: Conf. Series 953, 2017.

[11] S. Djamhari, "Biokompos cair dan pupuk kimia NPK sebagai alternatif nutrisi pada budidaya tanaman caisim teknik hidroponik," Jurnal Sains dan Teknologi Indonesia, vol. 14, pp. 234-238, March 2013.

[12] S.W. Rachmawati, "Pengaruh konsentrasi nutrisi AB mix pada sistem hidroponik rakit apung terhadap infeksi CMV pada tanaman mentimun", Bachelor thesis. Malang: Agriculture Faculty, University of Brawijaya, 2018.

[13] Nurfinayati, "Pemanfaatan berulang larutan nutrisi pada budibaya selada (latuca sativa L.) dengan teknologi hidroponik sistem terapung (THST)," Bachelor thesis, Bogor: Departemen Budidaya Pertanian Institut Pertanian Bogor, 2004.

[14] S. Long, "Jessie is here," Retrieved from Raspberry Pi official website, August 2018. https://www.raspberrypi.org/blog/raspbian-jessie-ishere/.

[15] Anonim, "Eclipse Mosquitto," Retrieved from Eclipse Mosquitto official website, August 2018. https://projects.eclipse.org/projects/technology.mosquitto.

[16] Anonim, "Why OpenHAB," Retrieved from OpenHAB official website, August 2018. https://www.openhab.org/.

[17] S. Barai, D. Biswas, and B. Sau, "Estimate Distance Measurement using NodeMCU ESP8266 based on RSSI Technique," Proceeding of IEEE Conference on Antenna Measurements \& Applications, December 2017.

[18] T. Yokotani, and Y. Sasaki, "Comparison with HTTP and MQTT on Required Network Resources for IoT," International Conference on Control, Electronics, Renewable Energy and Communications, January 2017. 